Journal of Extension Education

Vol. 29 No. 3, 2017

DOI:https: / / doi.org/10.26725/JEE.2017.3.29.5885-5891

\title{
Information Management Behaviour of Rice Farmers under Collective Farming in Kerala
}

\author{
Anusha Anwar ${ }^{1}$, P. Rambabu ${ }^{2}$ and T. Gopikrishna ${ }^{3}$
}

\begin{abstract}
The study was conducted in Kannur district of Kerala State, to assess the information management behaviour of rice farmers under the collective farming project of Kudumbashree mission. Expost facto research design was followed for the study. A sample of 120 farmers was selected by using proportionate sampling procedure and information was gathered and analyzed. The results showed that majority of the women rice farmers belonged to medium category of information management behavior.
\end{abstract}

Keywords : Information management; Information Input; Information Processing; Kerala

\section{INTRODUCTION}

Indian agriculture plays a major role in economic development. Besides technological advancement, extension plays a great role in agricultural development. Rapid changes in the agricultural scenario of the country are posing multiple challenges to the extension functionaries. Farmers need updated information on new, cost effective and adoptable crop production, post harvest and plant protection technology along with market information and weather reports. However, farmers are not accessible to all these. A big gap exists between the available technologies and their rapid transfer to the farmers. There is a gap between those who use ideas and those who produce them. A good technique of information management will certainly reduce this gap, if not eliminate it. The information management behaviour has been conceptualized as a composite measure of information seeking, evaluation, storage, utilization and dissemination behaviour of the individual farmer. Agricultural Information Management has been defined as the process of identifying, collection of information on agricultural technologies of origin, storing, updating and retrieving it whenever necessary to process, manipulate and disseminate the processed information to various users (Raju, 2005).

1. Ex-PG Scholar, 2. Professor \& Univ. head and 3. Professor, Department of Agricultural Extension, Agricultural College, Bapatla 522101, Andhra Pradesh. 
Rice cultivation has been the part and parcel of Kerala's culture and it is the state's major food crop. However, the area and production of paddy continues to be declining over the past 20 years. Large area of cultivable land is kept idle in the state due to the waning interest in agriculture. When paddy cultivation became a non-lucrative affair, farmers of the state deserted paddy fields. The Kudumbashree Mission of the state found this as an opportunity and in 2004, the programme on 'Collective Farming' by Joint Liability Groups was started under the Kudumbashree Mission which assists poor women to lease land in a group and thereby create an income source for them. Collective Farming Programme, also called as 'Harithashree' in local language, lends helping hands to those cultivators who are having no land at all.

Keeping this in view, the present research was carried out to study the 'Information Management Behaviour (IMB) of rice farmers under the collective farming of the Kudumbashree Mission in Kannur district of Kerala' with the following objectives:

* To study the personal, socio-economic and psychological characteristics of the rice farmers.

* To study the information management behavior of rice farmers.

* To unearth the relationship between information management behavior and the selected independent variables

\section{METHODOLOGY}

The research design adopted for the present study was ex-post-facto, since the phenomenon of Information management behaviour (IMB) had already taken place. The Kannur district of Kerala state was selected as it is one of the districts where the collective farming under the Kudumbashree has been successful in its attempt. Out of 11 blocks in Kannur, two blocks namely Thaliparamba and Kalliasseri were selected purposively for the study, where the number of rice farmers under the collective farming of Kudumbashree was comparatively high. From each block selected, six villages were purposively selected based on the highest number of rice farmers doing collective farming successfully under the Kudumbashree mission. Thus, a total of 12 villages were selected from the two blocks and 10 members from the selected villages, thus, in all, 120 women rice farmers were selected.

The data from the respondents were collected through personal interview method with the help of an interview schedule in an informal atmosphere either at home or at field. The mean, standard deviation and correlation co-efficiency were worked out for interpretation of results. The characteristics of respondents namely age, education, occupation, farming experience, family size, land holding, marriage status, annual income, social participation, extension contact, training 
Information Management Behaviour of Rice Farmers under Collective Farming in Kerala

received, loan borrowing and utilization behaviour, economic motivation, scientific orientation and market orientation were selected as independent variables.

The dependent variable for the study was Information Management Behaviour which was studied on three dimensions viz., information seeking, information processing and information dissemination behaviour. In the context of the present study, the information management behaviour (IMB) was operationally defined as the activities performed by an individual farmer for seeking, processing and dissemination of information with regard to the improved cultivation practices of rice crop.

The information seeking behaviour refers to the activities performed by an individual women rice farmer in relation to acquisition of scientific information with regards to the improved cultivation practices of rice crop from various information sources.

Information processing referred to all the activities performed by the women rice farmers for evaluation, storage and utilization of information.

Information dissemination behaviour was operationalized as the activities performed by the women rice farmers to disseminate the information regarding rice cultivation.

\section{FINDINGS AND DISCUSSION}

A majority of the rice farmers belonged to middle age (70.83\%). Age influences the behaviour of an individual by exposing to varied situations. Therefore, the influence of age of the women rice farmers was considered an essential aspect in this investigation. Majority $(40.00 \%)$ of the women rice farmers of Kudumbashree belonged to high school level of education, ie., more than one-third of the rice farmers (40.00\%) were well educated. This may be due to the importance given for education by the state government. Around onethird of the beneficiaries were employed in agriculture and animal husbandry. This might be because the job requires less training and was traditionally followed by the members. Majority $(57.50 \%)$ of the women rice farmers had farming experience of more than 15 years which enables them to understand and communicate the agricultural information effectively. Majority (52.50\%) of the women rice farmers had medium family size. The members from medium family size might have taken initiative in joining Kudumbashree.

A vast majority (93.33\%) of the women rice farmers belonged to the marginal land holding category i.e. less than 2.5 acres. Very few of them belonged to small land holding category which can be justified by the fact that majority of the women rice farmers were living below poverty line and thus hold very less land. This established the fact that majority of the women rice farmers 
of Kudumbashree were poor and joined to improve their socio-economic status. Generally by the age of 20, rural girls get married. These married women might have joined Kudumbashree in order to earn some income and save money, thus a majority $(74.17 \%)$ of the women rice farmers of Kudumbashree was married.

The present study revealed that over three-fourths of the women rice farmers belonged to medium income category, i.e. earning between Rs.10,000 $40,000 /-$ per month. This may be because Kudumbashree has been conceived as a mechanism to uplift the downtrodden women especially for those who are below poverty line. Nearly two-thirds $(81.67 \%)$ of the women rice farmers had medium level of social participation. More participation was shown by members who had received higher education and who are from supporting family background. Majority of the women rice farmers $(84.17 \%)$ had very good extension contact which shows that women rice farmers could improve their extension contact of the women after joining the Kudumbashree mission. Majority of the women rice farmers $(74.80 \%)$ had undergone both skill and knowledge based training. More than half $(52.50 \%)$ of the women rice farmers had medium loan borrowing and utilization behaviour. Further, most of the women rice farmers $(82.50 \%)$ had medium level of economic motivation, which might be due to reason that majority of women rice farmers had medium and small land holdings and are mostly engaged in agriculture for

Table 1.

Dimensions of Information Management Behaviour

\begin{tabular}{|c|c|c|c|}
\hline \multirow{2}{*}{ S1. No. } & \multirow{2}{*}{ Behaviour } & \multicolumn{2}{|c|}{ Women rice farmers } \\
\hline & & Frequency & Percentage \\
\hline \multirow{4}{*}{1.} & Information seeking behaviour & & \\
\hline & Low $(<46.84)$ & 13 & 10.83 \\
\hline & Medium ( $46.85-58.44)$ & 98 & 81.67 \\
\hline & High $(>58.44)$ & 9 & 7.50 \\
\hline \multirow[t]{4}{*}{2.} & Information evaluation behaviour & & \\
\hline & Low $(<29.94)$ & 11 & 9.17 \\
\hline & Medium $(29.95-34.81)$ & 87 & 72.50 \\
\hline & High $(>34.81)$ & 22 & 18.33 \\
\hline \multirow[t]{4}{*}{3.} & Information dissemination behaviour & & \\
\hline & Low $(<12.63)$ & 13 & 10.83 \\
\hline & Medium (12.64 - 18.34) & 92 & 76.67 \\
\hline & High $(>18.34)$ & 15 & 12.50 \\
\hline
\end{tabular}


their livelihood. More than two- thirds $(87.50 \%)$ of the women rice farmers had medium scientific orientation which might be due to their better education, extension contact and economic motivation that helped them to develop better scientific orientation. Kudumbashree has started more marketing centers, conducted more trade fairs and organizes monthly markets which may be the reason behind the majority of the respondents (80.83\%) falling under the medium market orientation category.
The detailed analysis of the dimensions of information management (Table 1) reveals that the majority of the respondents was belonging to medium category. The same trend was observed in all phases of Information Management Behaviour. The reasons for majority of them falling under medium information management behaviour might be due to better education, more trainings undergone, better economic motivation, and better scientific and market orientation.

Table 2.

Relationship between Independent Variables and Dependent Variable

\begin{tabular}{|c|l|r|}
\hline $\begin{array}{r}\text { S1. } \\
\text { No. }\end{array}$ & \multicolumn{1}{|c|}{ Independent variables } & \multicolumn{1}{|c|}{ ' $\mathbf{r}^{\prime}$ values } \\
\hline 1. & Age & $-0.0231 \mathrm{NS}$ \\
\hline 2. & Education & $0.5750^{*}$ \\
\hline 3. & Occupation & $-0.1385 \mathrm{NS}$ \\
\hline 4. & Farming experience & $0.0886 \mathrm{NS}$ \\
\hline 5. & Family size & $0.0918 \mathrm{NS}$ \\
\hline 6. & Land holding & $-0.0717 \mathrm{NS}$ \\
\hline 7. & Marital status & $0.2336^{*}$ \\
\hline 8. & Annual income & $0.3772^{*}$ \\
\hline 9. & Social participation & $0.4863^{*}$ \\
\hline 10. & Extension contact & $0.4943^{*}$ \\
\hline 11. & Training undergone & $-0.0652 \mathrm{NS}^{-1}$ \\
\hline 12. & Loan borrowing and utilization behaviour & $0.3212^{*}$ \\
\hline 13. & Economic motivation & $0.4117^{*}$ \\
\hline 14. & Scientific orientation & $0.3350^{*}$ \\
\hline 15. & Market orientation & \\
\hline
\end{tabular}

From Table 2, it is observed that education, annual income, social participation, extension contact, training received, economic orientation, scientific orientation and market orientation was found to be positively significant with 
the information management behaviour at 0.05 level of probability. Whereas age, occupation, farming experience, family size, land holding, marital status and loan borrowing \& utilization behaviour were found to be non-significant. The women rice farmers irrespective of their age had the same information sources and channels used for dissemination of agricultural information to the farmers. The comprehensive ability of an individual enhance with possessing educational qualification, which facilitates to understand various information input and output channels. The women rice farmers irrespective of their occupation had the same information channels used as source and for dissemination of agricultural information. The farming experience of the farmers does not bear any relation with information managing skills of the women rice farmers. The family size did not significantly influence the information management behaviour of the women rice farmers. Also the women rice farmers irrespective of their land holding, marital status and nature of the loan had the same level of exposure to different channels of agricultural information.

There was a positive and significant relationship between annual income and information management behaviour of the women rice farmers. When annual income increases, it helps in more accessibility to various channels of agricultural information. It can be visualized that social participation played an important role in IMB of women rice farmers. High social participation can naturally be aware of various channels of information and their effective utilization. Further, it is also likely that they have frequent contacts with the extension agencies like Kudumbashree agencies and panchayath offices thereby acquiring more information. IMB was also positively correlated with training received as trainings impart the knowledge skills about utilization of all the available channels to the effective communication of agricultural information to the farmers. Women rice farmers with more economic motivation would be oriented towards effective agricultural information channels. Farmers having good scientific orientation will naturally prefer to know the various sources information channels, their utilization and dissemination. Women who might have good orientation towards market news, information sources, facilities and networks were able to disseminate the latest information through various channels.

It could be concluded from the findings that education, social participation, extension contact, training received, economic motivation, scientific orientation and market orientation had contributed significantly to the information management behaviour of the women rice farmers. 


\section{CONCLUSION}

Factors like education, annual income, social participation, extension contact, training received, economic motivation, scientific orientation and market orientation influenced the information input, information processing, information output and overall information management behaviour of women rice farmers. Hence any improvement on these characteristics may bring significant change in the overall information management behaviour of rice farmers.

The findings also indicated that information management behaviour with regard to modern channels, like internet and website is very meager.

\section{REFERENCES}

Aparna, R., Meti, S.K \& Goudappa, S.B. (2014). Information Management Behaviour of papaya growers of Karnataka: A comparative study. Indian Research Journal of Extension Education. 14 (2): 31-35.

Raju, D. (2005). Agricultural information management behaviour of Indian farmers. 22nd Annual Conference Proceedings, Retrieved from https:// www.aiaee.org/attachments/ article/852/535.pdf.

State Planning Board, Government of Kerala. (2012). Evaluation Study on Kudumbashree - A Report. Evaluation Division. 